\title{
La justicia social en la oratoria de Fidel Castro: potencialidades para el docente universitario de historia
}

\section{Social justice in the rhetoric of Fidel Castro: potentialities for the university history teacher}

\author{
Mayelín Magdely Ruiz Álvarez * \\ Rosa María Rodríguez Carmona**
}

\begin{abstract}
* Profesora de la Universidad "José Martí Pérez" de la provincia Sancti Spíritus, Cuba. Licenciada en Educación en la especialidad de Historia. Profesora auxiliar y Máster en Ciencias de la Educación Mención Educación de adultos. Entre sus recientes publicaciones se encuentran: "La educación para la identidad cultural: un reto para el profesor universitario", en Revista Atlante, (octubre 2017). "El pensamiento ético de Fidel Castro en torno a la ciencia y la tecnología, en Revista Caribeña de Ciencias Sociales (febrero 2018). Es investigadora del Proyecto Asociado al Programa Nacional: "Acciones para desarrollar la identidad cultural en el contexto actual de la sociedad espirituana”.Correo electrónico: mayelin@uniss.edu.cu
\end{abstract}

\section{http://orcid.org/0000-0002-3971-9333}

** Profesora de la Universidad "José Martí Pérez" de la provincia Sancti Spíritus, Cuba. Licenciada en Educación en la Especialidad de Historia. Profesora Auxiliar y Máster en Educación Superior. Imparte como docencia de pregrado la asignatura de Economía Política. En la actividad de posgrado imparte Cursos en temáticas como: "La dimensión ética del desempeño docente desde el pensamiento pedagógico de Martí y Fidel”. Investigadora en temas relacionados con "La dimensión ética del desempeño docente desde el pensamiento pedagógico de Martí y Fidel", "La identidad cultural y los retos para profesores universitarios ante la avalancha de la cultura de masas". Autora de artículos cientificos y trabajos presentados en Eventos Internacionales como "Pedagogía 2015" y "Yayabociencia 2015", vinculados a temáticas de Historia e identidad cultural. Correo electrónico: rcarmona@uniss.edu.cu

http://orcid.org/0000-0002-3856-1263

Historial editorial

Recibido: 12-abril-2019

Aceptado: 06-agosto-2109

Publicado: 23-septiembre-2019

ISSN-e: 2594-2956 
La justicia social en la oratoria de Fidel Castro: potencialidades para el docente universitario de historia

\section{Resumen}

En el contexto cubano contemporáneo, la educación de estudiantes universitarios, cuyos modos de actuación se sustenten en el respeto a la igualdad social de los seres humanos, constituye un gran reto. Paradigma continental y mundial en la lucha por alcanzar plena justicia social, es sin lugar a dudas Fidel Castro, cuyo pensamiento se formó en medio de la Cuba dominada por el gobierno oligárquico de Estados Unidos y luego del triunfo revolucionario, se forjó en el batallar por la reivindicación de los derechos del hombre. El presente artículo pretende reflexionar en torno a las ideas de justicia social en la oratoria de Fidel Castro, las cuales constituyen un referente obligado para los docentes de Historia.

Palabras clave: justicia, justicia social, pensamiento ético, Fidel Castro, profesor universitario. 
Social justice in the rhetoric of Fidel Castro: potentialities for the university history teacher

\begin{abstract}
In the contemporary Cuban context, the education of university students whose modes of action are based on respecting the social equality of human beings represents a great challenge. Fidel Castro represents without a doubt a continental and global paradigm in the struggle to achieve social justice. His way of thinking was formed in the midst of Cuba dominated by the oligarchic government of the United States and then, after the revolutionary triumph, it was forged in the battle for the vindication of human rights. This article aims at reflecting on the ideas of social justice in the rhetoric of Fidel Castro, which constitute a mandatory reference for history teachers.
\end{abstract}

Keywords: justice, social justice, ethical thinking, Fidel Castro, university professor. 
Justice sociale dans l'oratoire de Fidel Castro: potentialités pour le professeur d'histoire à l'université

\section{Résumé}

Dans le contexte cubain contemporain, l'éducation des étudiants universitaires, dont les modes d'action sont basés sur le respect de l'égalité sociale des êtres humains, constitue un grand défi. Paradigme continental et mondial dans la lutte pour une justice sociale totale, c'est sans aucun doute Fidel Castro, dont la pensée s'est formée au milieu de Cuba, qui était dominée par le gouvernement oligarchique des ÉtatsUnis et qui, après le triomphe révolutionnaire, s'est forgée la revendication des droits de l'homme. Cet article a pour objectif de réfléchir aux idées de justice sociale dans l'oratoire de Fidel Castro, qui constituent une référence obligatoire pour les professeurs d'histoire.

Mots-clés: Fidel Castro, Justice, Justice sociale, Pensée éthique, Professeur d'université. 
Idea prawiedliwosci spolecznej $\mathrm{w}$ przemowach Fidela Castro: mozliwosci dla wykladowcy historii na uniwersytecie.

\section{Streszczenie}

We współczesnym kubańskim kontekście edukacja studentów bazuje się na poszanowaniu społecznej równości istot ludzkich, jednoczesnie jest ona jest wielkim wyzwaniem we współczesnym swiecie. Kontynentalnym i globalnym paradygmatem w walce o osiągnięcie pełnej sprawiedliwości społecznej, jest niewątpliwie Fidel Castro, którego filozofia rozwinela się w polowie ubieglego stulecia na Kubie zdominowanej przez oligarchiczny rzad Stanów Zjednoczonych i po rewolucyjnym triumfie, została zafałszowana przez kapitalistyczny swiat. Artykul jest próba refleksji na temat sprawiedliwosci spolecznej w przemowieniach Fidela Castro, jako przyklad do naucznia historii na uniwerytecie.

\section{Slowa kluczowe:}

Sprawiedliwosc, sprawiedliwosc spoleczna, etyka, Fidel Castro, wykladowca. 


\section{Introducción}

"No vivo en una sociedad perfecta" (Milanés, 1982, canción 6) constituye parte del estribillo de una de las melodías más emblemáticas que han acompañado la construcción de un país, que vive en una sociedad perfectible en toda su extensión.

Sin la pretensión del análisis de la misma, se recurre a ella como expresión de que, en el más controversial de los escenarios, el hombre necesita vivir en una sociedad lo más cercana a la justicia. Para ello debe ser educado en comunidades que propendan a ello.

Al referirse al contenido axiológico que debe tener la educación en la sociedad, Fidel Castro Ruz expresó:

Educar es todo, educar es sembrar valores, es desarrollar una ética, una actitud ante la vida. Educar es sembrar sentimientos. Educar es buscar todo lo bueno que puede estar en el alma de un ser humano, cuyo desarrollo es una lucha de contrarios, tendencias instintivas al egoísmo y a otras actitudes que han de ser contrarrestadas y sólo pueden ser contrarrestadas por la conciencia (Castro, 200I, p. 2).

El contexto histórico que existía en Latinoamérica y, en particular, en Cuba de los años cincuenta del siglo XX, caracterizado por la injusticia social, la pobreza y el subdesarrollo, le da sentido al pensamiento de Fidel, el cual, ofrece potencialidades en este aspecto, ya que constituye: “...uno de los pensamientos políticos y sociales más lúcidos, creativos y anticipadores de la humanidad en el último medio siglo de su historia" (Álvarez, 2008, p. 2). 
¿En qué componentes ideológicos abreva el pensamiento social de Fidel Castro, en particular, el de justicia social? Su ideología, de corte socialista, es expresión suprema de la lucha por la justicia, encontrándose en sus pronunciamientos una lucha tenaz contra la pobreza material y ética que padecen los países emergentes, hoy acentuadas con la puesta en práctica por parte del imperialismo, del neoliberalismo, entendido como etapa del desarrollo económico, político y social que asume el imperialismo.

Entre las razones básicas que permiten plantear la necesidad de la utilización de su pensamiento en la educación en valores están:

- La riqueza de su proyección ética, que conduce a la idea del hombre nuevo, a partir de su inteligencia y conocimientos científicos y tecnológicos.

- Su elevada moral, valores, sensibilidad, nobles sentimientos y humanismo, en correspondencia con una realidad social y contexto más humanos. La formación de esa nueva personalidad constituye un proceso complejo si se tienen en cuenta las propias dificultades que encierra la construcción de la sociedad socialista en un país subdesarrollado que enfrenta como enemigo principal al imperio más poderoso del planeta.

En el pensamiento de Fidel se pueden encontrar importantes reflexiones sobre la justicia social y la necesidad de que esta sea impuesta a escala planetaria. Sus ideas colocan al hombre ${ }^{\mathrm{I}}$ como centro de todo. Su vida, su pensamiento y su obra están destinados a hacer más racional la vida humana.

Investigadores se han ocupado del estudio de la vida y obra de Fidel Castro, así también, se han enmarcado en el análisis de aristas de su 
pensamiento y/o acción; sin embargo, en el tema que nos ocupa existen vacíos, si se reconoce que no se encuentran estudios que aborden las potencialidades que ofrece la justicia social desde la oratoria de Fidel, para los profesores de Historia de la universidad cubana actual.

El presente trabajo es resultado de un proceso de selección de discursos de Fidel. Indudablemente, este análisis exigió un examen riguroso que reconoce la oralidad del líder revolucionario en la defensa de la construcción de un mundo mejor, de justicia social.

Toda selección de discursos referidos a este tema es indudablemente un riesgo, puesto que solo expresa un acercamiento al asunto seleccionado y por lo tanto no constituye un trabajo totalmente concluido. No obstante, sus pronunciamientos en defensa de la justicia pueden calificarse como constante en tribunas nacionales e internacionales donde estuvo presente.

Constituye este documento un material de consulta para profesores y/o estudiantes universitarios, quienes encuentran en él valoraciones personales, de biógrafos y otras personalidades de renombre que redundan en la formación y desarrolla de las ideas de justicia social en el pensamiento de Fidel Castro, a lo que se integran las claves metodológicas a tener en cuenta por los docentes de Historia, para la educación universitaria basada en este valor.

Reconociendo la permanente lucha mundial por un mundo de justicia, así como la necesaria misión de los docentes universitarios de educar a las jóvenes generaciones acorde a los valores de una sociedad plena y decorosa, el presente artículo pretende reflexionar en torno a las ideas de justicia social en la oratoria de Fidel Castro, las cuales constituyen un referente obligado para los docentes de Historia. Encuéntrese en ello 
la aportación al campo de la historia y en especial a la enseñanza de valores en dicha asignatura a nivel universitario

\section{Acercamiento necesario a la justicia social como valor}

El término justicia es abordado desde diferentes puntos de vista. El Diccionario Manual e Ilustrado de la Lengua Española lo define como la "virtud que nos inclina a dar a cada uno lo que le corresponde. Derecho, razón, equidad. Conjunto de todas las virtudes que constituye bueno al que las tiene" (Real Academia Española, 1970, p. 90I).

Por su parte el Diccionario de la Lengua Española de la Real Academia precisa que el término proviene del latín Iustitia y en su primera acepción se refiere a la virtud que inclina a darle a cada uno lo que le pertenece (Real Academia Española, 1970, p. 777).

En el Diccionario Enciclopédico Color se define como el "orden de convivencia humana que consiste en la igualdad de todos los miembros de la comunidad. Comportamiento justo, equidad, rectitud" (Diccionario Enciclopédico Color, 1998, p. 523).

Un reconocimiento a partir de la pluralidad de concepciones en esta literatura, permite ver la existencia de claves semánticas al abordar el término. Tal es el caso de la justicia, que queda registrada desde el punto de vista lingüístico como una virtud que se dirige a lo equitativo, a la igualdad, a lo racional.

Desde la perspectiva filosófica, el término aparece definido en contraposición al término injusticia, entendido entonces como "principios éticos que expresan una diferente valoración moral de los 
fenómenos sociales. Justificación y aprobación de algún fenómeno social al que se reconoce justo o desaprobación y condena del fenómeno considerado injusto." (Rosental y Iudin, 1984, p. 254).

Otra concepción en torno al término, queda expresada como:

[...] orden de las relaciones humanas o de la conducta del que se adapta a este orden, distinguiendo dos significados principales: I) El significado según el cual la justicia es la conformidad de la conducta a una norma y 2) Aquel por el cual la justicia constituye la eficiencia de una norma o de un sistema de normas (Abbagnano, 2004, p. 713).

La noción de justicia hay que buscarla en los más remotos orígenes del pensamiento jurídico griego, donde sufre una evolución desde las primeras ideas presentes en el mundo familiar gentilicio, hasta ser sustituida por la justicia política en la sociedad dotada ya de Estado. Sin embargo, en todo caso se apela a una divinidad para derivar de ella la acción justa, la aplicación de la norma primero social y después legal. A ese derecho primitivo tenían alcance solamente los hombres pertenecientes a la aristocracia.

Por tal motivo, en las reflexiones que sobre la justicia se encuentran en los pensadores de aquella etapa, está siempre presente la defensa del orden esclavista existente. Así por ejemplo, Aristóteles -considerado por Lenin la mente más enciclopédica de la antigüedad- planteó que:

En tanto que el transgresor de la ley es injusto, mientras que quien se conforma a la ley es justo; en efecto, las cosas establecidas por el poder legislativo son conforme a la ley y decimos que cada una de ellas es justa (Abbagnano, 2004, p. 713). 
En el desarrollo del pensamiento filosófico existió la tendencia a identificar la justicia con la felicidad. Para Aristóteles:

Las leyes se pronuncian sobre todo tendiendo a la utilidad común de todos o a la que predomina por la virtud o de otra manera, de suerte que mediante una sola expresión definimos como justas las cosas que procuran o mantienen la felicidad, o parte de ella, a la comunidad política (Abbagnano, 2004, p. 715).

En Santo Tomás de Aquino se encuentran reflexiones como: "La identificación del bien con la beatitud eterna es un caso particular de esta doctrina" (Abbagnano, 2004, p. 715). Otra tendencia es la de relacionar los términos justicia y utilidad.

En el mundo moderno Hume dio validez a este punto de vista planteando que: "La utilidad y el fin de la justicia es procurar la felicidad y la seguridad conservando el orden en la sociedad" (Abbagnano, 2004, p. 715).

Otra opinión acerca del tema es la que identifica la justicia con la libertad, la cual fue formulada por Kant. En tal sentido expresó:

Una sociedad en la cual la libertad bajo leyes extremas se enlace en el más alto grado posible con un poder irresistible. O sea una constitución civil perfectamente justa es la tarea suprema de la naturaleza con relación a la especie humana (Abbagnano, 2004, p. 715).

En el pensamiento moderno comienza a introducirse un nuevo elemento como medida o criterio de la justicia: la paz. Converge en esta dirección el filósofo Hobbes quien consideraba que un comportamiento justo es un ordenamiento que garantiza la paz, 
sustrayendo a los hombres del estado de guerra de todos contra todos, al que los reduce el ejercicio del derecho natural. Para este pensador, la primera ley de la naturaleza es la norma que prescribe la paz.

En la historia del pensamiento cubano destaca la figura de José Martí, quien en su proyecto emancipador contempló a la justicia como necesidad impostergable en el logro del mejoramiento humano. En sus obras se encuentran ideas como las siguientes: “¿Qué mundo es este, donde la justicia muere sola, o sólo triunfa por convertirse en injusticia interesada y potente? (Martí, I965, p. I47). Relaciona el cumplimiento de la justicia con el valor cuando afirma: "La justicia no menoscaba el valor; antes lo enaltece” (Martí, I965, p. I40).

Al referirse a la necesidad de ponerlo todo en función de la justicia apuntó: "Se pelea mientras hay por qué, ya que puso la Naturaleza la necesidad de justicia en unas almas, y en otras la de desconocerla y ofenderla. Mientras la justicia no esté concedida, se pelea" (Martí, 1965, p. 83).

La justicia primero, y el arte después. Hembra es el que en tiempos sin decoro se entretiene en las finezas de la imaginación, y en las elegancias de la mente. Cuando no se disfruta de la libertad, la única excusa del arte y su único derecho para existir es ponerse al servicio de ella. Todo al fuego, hasta el arte, para alimentar la hoguera (Martí, I965, p.433).

En Martí hay un pensamiento de justicia de la perspectiva liberal progresista a diferencia de Fidel Castro, de pensamiento socialista; es cierto, hay una continuidad en el tránsito del liberalismo al socialismo, pero este responde a condiciones históricas específicas concretas. 
El concepto de justicia ha experimentado cambios en la medida que la sociedad se transforma en el tiempo. El socialismo como sistema establece relaciones sociales que implican igualdad de derechos, amistad, fraternidad y colaboración entre los hombres a nivel de país y entre todos los pueblos. Independientemente de las imperfecciones que como sistema puede tener, ofrece opciones viables para alcanzar un nivel de equidad social superior al resto de los sistemas que la humanidad ha conocido.

Roque Dalton, poeta salvadoreño, captó de manera singular esta esencia al expresar: "El Comunismo será, entre otras cosas, una aspirina del tamaño del sol” (Dalton, 2009, p. 3).

Las autoras de este trabajo asumen como definición de justicia la que concibe el Programa de Educación en Valores para la Escuela Cubana, teniendo en cuenta que en él se enfatiza la necesidad de considerar a todos los seres humanos en igualdad de condiciones dentro de la sociedad. Además, los elementos que se plantean se ajustan a la aspiración máxima del proyecto social cubano.

De esta manera se entiende por justicia social:

[...]el respeto a la igualdad social que se expresa en que los seres humanos sean acreedores de los mismos derechos y oportunidades, sin discriminación por diferencias de origen, edad, sexo, ocupación social, desarrollo físico, mental, cultural, color de la piel, credo y de cualquier otra índole (Ministerio de Educación de la República de Cuba [MINED], 2008, p. 5).

Contribuir a un desarrollo humano integral basado en la igualdad de oportunidad, defender con altura ética los derechos desde el cumplimiento de los deberes, mostrar indignación ante cualquier acto 
de injusticia que se cometa contra los seres humanos en cualquier parte del mundo y estar dispuesto a luchar por defender la justicia, constituyen, sin lugar a dudas, modos de actuación inherentes a la justicia social.

Formación y desarrollo de las ideas de justicia social en el pensamiento de Fidel Castro Ruz

Desde la concepción marxista la esencia humana es entendida como conjunto de las relaciones sociales. Siguiendo esa línea de análisis, es necesario reflexionar sobre el contexto histórico en que tiene lugar la formación y desarrollo de la personalidad de Fidel Castro: qué condicionantes histórico-sociales determinaron en él la conformación de un pensamiento que lo convierte en paradigma para Cuba y el mundo en la lucha por conquistar la justicia.

Fidel Castro Ruz nació el 13 de agosto de 1926, en Birán, un pequeño poblado de la actual provincia de Holguín, en la zona oriental de Cuba. Allí asistió a una escuelita pública y desarrolló el amor por los libros, bajo la influencia de los padres y habitantes de la zona. Al referirse a 168 esta primera influencia recibida en su formación, Fidel expresó: “[...] El primero fue el tenedor de libros de Birán, donde yo nací, que me hablaba hasta de Demóstenes y no sé de cuantos personajes de la historia [...]" (Castro, 2004, p. 2). 
El contexto familiar presenta un hogar donde se inculcan valores morales y se le prepara para la vida, con un padre terrateniente. Sufrió la inflexibilidad de los métodos escolásticos en los colegios católicos de La Salle y Dolores, en Santiago de Cuba y Belén, y en La Habana. Los recuerdos de esta época fueron motivo de sus reflexiones:

En realidad trataban de enseñarnos Geografía, pero no sabían enseñarnos Geografía [...] la Geografía resultaba una enumeración [...] monótona de accidentes de la naturaleza, sin que de veras se nos despertara el interés [...] Lo que habíamos aprendido de memoria [...] era lógico que fuera desapareciendo sin dejar huella alguna en nuestra mente (Castro, 2004, p. 2).

Se rebeló contra esos métodos y al referirse a la improductividad de los mismos, expresó:

[...] todo era muy dogmático. Esto era así porque tenía que ser así, hay que creerlo, aunque no se entienda, si no lo crees, aunque no lo entiendas, es una falta, un pecado, un acto digno de castigo. Es decir, la no utilización del razonamiento, yo diría, el no desarrollo del razonamiento y del sentimiento. Me parece que una fe religiosa, como una fe política, tiene que fundarse en el razonamiento, en el desarrollo del pensamiento y en el desarrollo del sentimiento, son dos cosas inseparables (Betto, I985, p. 132).

Desde muy temprano desarrolló la característica de pensar de manera independiente. En 1959 afirmó:

Yo era un niño privilegiado [...] Tengan en cuenta que a mí me pusieron 12 años a pupilo en un colegio religioso, con una enseñanza dogmática y yo soy sencillamente revolucionario. 
Soy revolucionario porque toda mi vida pensé con mi propia cabeza, toda mi vida me negué a aceptar las mentiras de otros. Soy revolucionario producto de mi propio análisis, de mi propio juicio, de mi propia observación de las realidades (Castro, 2004, p. 2).

No obstante, las limitaciones que el tipo de enseñanza religiosa de estos colegios ofrecía, la vida austera, rigurosa, llena de sacrificios y amor al trabajo que caracterizaba a los jesuitas, fueron cuestiones decisivas en la formación de su carácter.

El amor a la naturaleza y su afición por el deporte contribuyeron también al fortalecimiento de una personalidad inspiradora, que gustaba de las situaciones riesgosas y difíciles, para poner a prueba su espíritu emprendedor y tenaz. La dignidad personal, el sentido del honor, la franqueza, la rectitud, la valentía, fueron valores que los jesuitas supieron inculcar.

En el álbum de graduación del Bachillerato, en el Colegio de Belén de los jesuitas, en la página correspondiente al estudiante Fidel Castro Ruz, el sacerdote de origen español, Armando Llorente, escribió: "Fidel tiene madera, no faltará el artista...” (Betto, 1985, p. 313).

En su formación incidió además su relación con personas pobres que le ayudaron a conformar un sentido de justicia, pues la desigualdad social imperante le enseñó a luchar contra ella. Las características del hogar en que nace, o sea, el hecho de ser hijo de terrateniente y no nieto, determinaron que su vida transcurriera no precisamente en un ambiente aristocrático. En Birán conoció de cerca la pobreza. 
Sus recuerdos de esta etapa lo remontan a las filas de desempleados analfabetos que hacían colas en las proximidades de los cañaverales, sin que nadie les llevara una gota de agua, ni desayuno. No tenían albergue, ni transporte.

$\mathrm{Al}$ referirse al papel que jugaron estas circunstancias en la formación de su ideal de justicia social, Fidel expresa:

[...] creo que toda la vida tuve una idea de lo justo y de lo injusto, y bastante temprano porque lo viví y lo sufrí [...] Creo que un conjunto de cosas me hicieron, primero, poseer ciertas normas éticas, y luego, la vida me hizo imposible adquirir una cultura de clase, una conciencia de una clase diferente y superior a la otra [...] esa fue la base con la cual después desarrollo una conciencia política [...] en mi caso, no la adquiero porque proceda de una clase pobre, proletaria, campesina, humilde, no la adquiero por mis condiciones sociales, mi conciencia la adquiero a través del pensamiento, a través de la razón, y a través del desarrollo de un sentimiento y de una convicción profunda. (Ramonet, 2006, p. 52).

Fidel estuvo al tanto, desde su adolescencia, de acontecimientos internacionales que sin lugar a dudas también marcaron su pensamiento. Siguió de cerca los detalles sobre la Guerra Civil en España, lo que significó para el pueblo la caída de la Republica y cómo este hecho contribuyó a dar paso a la II Guerra Mundial. De este acontecimiento en particular leyó sobre la toma del Ruhr, la anexión de Austria y la invasión a Polonia.

El pensamiento ético de Fidel Castro, caracterizado por un profundo humanismo, como el que se expresa en la entrega total a la Revolución 
Cubana y a las causas más justas existentes hoy en el mundo, posee una profunda raíz martiana. Al respecto Ramonet señala: "Cita a José Martí, el héroe de la independencia de Cuba, mucho más que a ningún otro personaje de la historia del movimiento socialista u obrero. Martí constituye su principal fuente de inspiración" (Ramonet, 2006, p. 27).

La lectura de los textos martianos durante su adolescencia lo convierte en un simpatizante de sus ideas y fue importante contribución en la formación de una cultura política sólida desde su juventud. La admiración que sentía Martí, por los luchadores cubanos y que dejó expresada en sus discursos de estilo peculiar, en conmemoración al ıo de octubre y al 27 de noviembre, jugaron un rol esencial en la formación de su pensamiento patriótico. El propio Fidel Castro los califica como: "[...] una catarata de ideas en un pequeño arroyo de palabras" (Ramonet, 2006, p. 52).

Consultando la obra martiana conoció Fidel su concepción de la República con todos y para el bien de todos con la que soñó el Apóstol, la organización del partido y su significado en el logro de la unidad en la Revolución, su crítica profunda al imperialismo norteamericano y sus pretensiones de apoderarse de América Latina, así como sus simpatías por los trabajadores.

El independentismo, antimperialismo y latinoamericanismo consecuentes, que caracterizan el pensamiento martiano, aportaron valores éticos inigualables al pensamiento revolucionario de Fidel Castro, quien asumió consecuentemente el precepto martiano de que toda la gloria del mundo cabe en un grano de maíz.

Sobre el significado de esta frase el propio Fidel ha expresado: 
Lo que me agrada especialmente de la frase de Martí es la idea de la insignificancia del hombre en sí, ante la enorme trascendencia y la magnitud inabarcable del universo, la realidad de que somos realmente como un minúsculo fragmento de polvo que flota en el espacio. Mas esa realidad no disminuye un ápice la grandeza del hombre; por el contrario la eleva... (Castro, I999, p. 45).

Un aspecto a destacar es la influencia que la cultura francesa dejó en su formación intelectual y en la construcción de su ideario político:

La lectura de Los miserables de Víctor Hugo realizada en la adolescencia, por su contenido social y político, ejerció una influencia indirecta en la manera de ver el mundo y sus injusticias, así como la necesidad de luchar para corregirlas. Esta obra es, junto con El Quijote, de Cervantes, la obra narrativa que más le ha impactado (Ramonet, 2006, p. I62).

Otros autores que dejaron sus huellas son Honoré de Balzac y Romain Roland. De este último, su "Juan Cristóbal", extenso relato que considera una reivindicación del ser humano. Entre los escritores europeos que más admira están: Honoré de Balzac, Fiodor Dostoievski, León Tolstoi y Benito Pérez Galdós.

En septiembre de 1945 se matricula en la Facultad de Derecho de la Universidad de La Habana, vinculándose a la Federación Estudiantil Universitaria (FEU) y al Partido del Pueblo Cubano (Partido Ortodoxo). En abril de I948, cuando asistía a la IX Conferencia Internacional Interamericana, al frente de una delegación de la FEU, participó en la insurrección del pueblo colombiano conocida como el "Bogotazo", 
motivada por el asesinato de Jorge Eliécer Gaitán, quien representaba una esperanza de paz y desarrollo para ese pueblo.

Sobre lo que aportó esa experiencia en su formación revolucionaria expresó:

[...] me hizo identificarme más con la causa de los pueblos. Las ideas marxistas, todavía incipientes, no tuvieron nada que ver con nuestra conducta, fue una reacción espontánea de nuestra parte, como jóvenes con ideas martianas, antimperialistas, anticolonialistas, y predemocráticas (Ramonet, 2006, p. 138).

En este mismo año visitó Venezuela, Panamá y Colombia, organizando un Congreso Latinoamericano de Estudiantes, cuyo objetivo era demandar la soberanía panameña sobre la zona del Canal, exigir la independencia de Puerto Rico y reclamar la eliminación del colonialismo. Fue miembro activo del Comité Pro-Democracia Dominicana.

En 1950 obtuvo los títulos de Licenciado en Derecho Diplomático y Doctor en Derecho Civil, lo cual exigió mucho tiempo frente a los libros. Al valorar esta etapa tan importante de su vida, expresó:

Y si le digo que en esa universidad me hice revolucionario, fue porque hice contacto con algunos libros [...] en lo que yo me había convertido ya, antes de encontrarme con el material marxista o leninista, era en un comunista utópico. Comunista utópico es el que no parte de una base científica ni histórica, sino de algo que le parece muy mal, de la existencia de la pobreza, injusticias, desigualdades, una insuperable contradicción entre sociedad y verdadero desarrollo (Ramonet, 2006, p. I40). 
La lectura de obras marxistas como El Manifiesto Comunista o El Estado y la Revolución contribuyeron a completar su pensamiento político y revolucionario. Valorando las influencias fundamentales en su formación, destaca lo siguiente:

De Martí, inspiración, su ejemplo y muchas cosas más; pero sobre todo la ética [...] La ética, como comportamiento, es esencial, y una riqueza que no tiene límites [...] De Marx recibimos el concepto de lo que es la sociedad humana [...] Marx nos mostró lo que era la sociedad y la historia de su desarrollo. Sin Marx, usted no puede encajar ningún argumento que interprete de forma razonable los acontecimientos históricos, cuáles son las tendencias y la evolución probable de una humanidad que no ha terminado de evolucionar socialmente. (Ramonet, 2006, p. I42).

Momento decisivo en su maduración revolucionaria lo constituye su estancia en la cárcel de Isla de Pino luego del asalto a los cuarteles Moncada y Carlos Manuel de Céspedes en 1953. Durante esa etapa perfeccionó su preparación cultural y científica de manera autodidacta. En esta época escribe: "No he perdido tiempo en la prisión, estudiando, observando, analizando, planeando, forjando hombres" (Mencia, 1980, p. I49).

Dentro de la cárcel fundó la Academia Ideológica: "Raúl Gómez García" donde funge como profesor de asignaturas como Filosofía e Historia Universal, constituyendo no sólo un guía espiritual por sus ideas y sus acciones políticas, sino también porque se convierte en maestro de asignaturas dirigidas a fortalecer la ideología y la cultura política de los que luchaban a su lado. 
Por las noches impartía Economía Política y dos veces a la semana también Oratoria. No faltó Martí entre los temas de sus clases. En esos días leyó a Martí, Víctor Hugo, Carlos Marx, Félix Varela, Luz y Caballero, Honoré de Balzac, Shakespeare, Rómulo Gallegos, Sigmund Freud, Dostoyevski, Kant, Cirilo Villaverde, biografías de Bolívar y a Lenin. Desarrolló además lecturas de clásicos griegos y romanos, así como de varios autores cubanos, latinoamericanos y rusos.

Sobre lo que significó esta etapa en su formación revolucionaria afirmó: "! Qué escuela tan formidable es esta prisión. Desde aquí termino de forjar mi visión del mundo y completar el sentido de mi vida!” (Mencia, I980, p. I49).

Puede afirmarse que el proceso de articulación del pensamiento nacional de avanzada y las tradiciones patrióticas, con el Marxismo Leninismo, que se da en la formación de la personalidad de Fidel Castro, le permitieron trazar una táctica y estrategia de lucha que condujo al pueblo de Cuba al triunfo definitivo. Desde 1959 hasta la actualidad sus ideas de justicia social se han materializado en la obra de la Revolución Cubana y en la batalla que en la arena internacional ha proyectado Cuba en favor de los pobres del mundo.

Puede enfatizarse que en la formación ética de Fidel Castro tienen una fuerte influencia factores de diversa naturaleza:

-Los que se refieren al contexto en que se desenvolvió y le aportaron una ética para valorar la realidad circundante, desde una situación en la que unos son favorecidos y otros no tienen nada. Los colegios aportaron valores como la perseverancia, constancia y respeto a los demás. 
-Los de carácter teórico que comprenden las teorías, escritos y literatura de la cual se nutrió básicamente su pensamiento. El estudio de las obras de los clásicos del Marxismo Leninismo y de José Martí, que conformaron su cosmovisión de carácter renovador, humanista y transformador de la realidad a partir de una incesante inconformidad con la injusticia y la dominación o explotación de personas o naciones por otras. Los estudios realizados de la literatura clásica universal, lo cual le incorporó una cultura que es base de todo su quehacer revolucionario. Los estudios de Historia de Cuba, le permitieron asimilar un conjunto de valores que refleja más tarde en la obra de la revolución y transmite al pueblo de Cuba en cada una de sus intervenciones (Cárdenas, 2007, p. I8).

En su pensamiento se pueden encontrar importantes reflexiones sobre la justicia social y la necesidad de que esta sea impuesta a escala planetaria. Sus ideas colocan al hombre como centro de todo. Su vida, su pensamiento y su obra están destinados a hacer más racional la vida humana.

Al referirse a esta importante cualidad de Fidel, Ignacio Ramonet apuntó:

Le guste o no a sus detractores, Fidel Castro tiene un lugar reservado en el panteón mundial consagrado a las figuras que con más empeño lucharon por la justicia social y que más solidaridad derrocharon a favor de los oprimidos de la Tierra (Ramonet, 2006, p. 24).

En este mismo sentido Osvaldo Martínez afirmó: 
Fidel posee un profundo sentido de la justicia social, pero no en el plano teórico y de grandes categorías abstractas, sino de acciones concretas [...] Su humanismo se traduce en acciones concretas. Es esa preocupación por los más desvalidos, por los sectores de la población en desventaja social, por mejorar la condición humana (Martínez, 2006, p. 6-7).

Sus valoraciones sobre el internacionalismo como el más sagrado deber de todo revolucionario y sobre las hermosas páginas que Cuba ha escrito a lo largo de los años de Revolución, constituyen un importante elemento en la formación de las nuevas generaciones. En la entrevista citada de Ramonet a Fidel Castro, el periodista valora muy en alto su conocimiento de la Historia, dejándolo expresado de la siguiente manera: "Posee un sentido de la Historia, profundamente anclado en él, y una sensibilidad extrema hacia todo lo que concierne a la identidad nacional" (Ramonet, 2006, p. 27).

Fidel no impone sus ideas, dialoga, reflexiona y se adapta a cualquier auditorio, no obstante su amplia cultura. En tal sentido enfatiza Gabriel García Márquez (I987):

Tiene un idioma para cada ocasión, y un modo distinto de persuasión, según los distintos interlocutores, [...] Sabe situarse en el nivel de cada uno, y dispone de una información vasta y variada que le permite moverse con facilidad en cualquier medio (p. 5-6).

Existe congruencia absoluta entre su pensamiento y acción. Es modesto y muestra una confianza ilimitada en el hombre al que considera capaz de conquistar un mundo mejor. 


\section{El valor justicia social en la oratoria de Fidel}

Fidel Castro desarrolla su pensamiento inmerso en la vida y la lucha política, él sintetiza la obra de los pensadores universales y cubanos que le precedieron, Marx, Lenin y Martí esencialmente. Sus ideas de justicia social han quedado plasmadas en numerosos textos.

Las autoras asumen para este artículo, la definición de texto dada por Magalis Ruiz Iglesias, quien plantea que: "Un texto es un acto oral o escrito, ideacional, discursivo e interpersonalmente coherente" (Ruiz, 1995, p. 3). Se ha tenido en cuenta la clasificación de los textos aportada por la misma autora en la obra citada. De carácter oral: En esta clasificación están los discursos, las conferencias radio-televisivas y las entrevistas. Hay registrados, más de II50 discursos públicos de Fidel Castro, a lo largo de 50 años de Revolución en el poder.

La palabra oral ha sido el instrumento preferente utilizado por Fidel para informar, esclarecer, explicar y orientar al pueblo, con los únicos propósitos de servir a la verdad y mantener y elevar la conciencia política de los cubanos (Álvarez, 2008, p. 3).

Sobre los rasgos de la oratoria de Fidel Castro, el Che afirmó:

En las grandes concentraciones públicas se observa algo así como un diálogo de dos diapasones cuyas vibraciones provocan otras nuevas en el interlocutor. Fidel y la masa comienzan a vibrar en un diálogo de intensidad creciente hasta alcanzar el clímax en un final abrupto, coronado por nuestro grito de lucha y de victoria (Guevara, I970, p. 370). 
García (1987) también se refiere a estas cualidades de la oratoria de Fidel subrayando:

Empieza siempre con voz casi inaudible, de veras entrecortada, avanzando entre la niebla con un rumbo incierto, pero aprovecha cualquier destello para ir ganando terreno palmo a palmo, hasta que da una especie de gran zarpazo y se apodera de la audiencia. Entonces se establece entre él y su público una corriente de ida y vuelta que los exalta a ambos y se crea entre ellos una especie de complicidad dialéctica, y en esa tensión insoportable está la esencia de su embriaguez. Es la inspiración: el estado de gracia irresistible y deslumbrante que sólo niegan quienes no han tenido la gloria de vivirlo (García, 1987, p. 5-7).

Los rasgos que caracterizan sus discursos y lo que se logra entre él y el público ha sido valorado por Fidel, definiéndolo de la siguiente manera:

[...] Generalmente llevo las ideas básicas, esenciales, cinco ideas, seis ideas fundamentales y un objetivo central de la exposición, entonces las desarrollo y mientras hablo se suscitan nuevas ideas y nuevos argumentos. Fluyen mejor las ideas cuando el discurso es eminentemente político, histórico, revolucionario, emotivo [...] He podido apreciar lo siguiente: el contacto con el público, la influencia del público, es la mejor fuente de inspiración, surgen repentinamente ideas y argumentos que a usted no le vienen a la mente con tiempo el día antes o muchos días antes. Cuando uno está en contacto con el público nada es artificial, nada es abstracto, surgen mejores cosas, las palabras son más persuasivas, más convincentes (Elliot y Dymally, 1985, p. 74-78). 
Comparecencia radio-televisiva: Fueron muy frecuentes en los años iniciales de la Revolución y retomados en cada momento que ha sido necesario explicar algunas situaciones de forma detallada al pueblo. Este tipo de comunicación tiene un fin esencialmente político, son eminentemente informativos, se distinguen por la transmisión del espíritu de una época o momento histórico, aportan detalles, diversidad de puntos de vista y permiten profundizar en la historia de la Revolución, son portadoras de información teórica para los docentes, y de las decisiones más trascendentales de la Revolución.

La lectura y análisis del pensamiento de Fidel Castro expuesto en sus discursos y entrevistas, permiten al profesor universitario de Historia, delimitar las ideas esenciales con relación a la justicia social que pueden ser utilizadas en función de la formación del estudiante.

Del análisis de los textos las autoras han inferido las siguientes claves que pueden servir de referente para su tratamiento en la docencia de Historia:

- Inevitabilidad de la revolución social como ley objetiva de la sociedad humana y vía insoslayable para alcanzar la plena justicia social.

- Comprensión del papel que corresponde al líder y a las masas en la Revolución.

- La justicia social está determinada por el cumplimiento de los derechos humanos esenciales.

- No puede haber justicia social sin democracia.

- La defensa de la cultura como vía para la definitiva liberación social del hombre.

- La historia, la identidad nacional y la cultural de los pueblos: armas en la lucha por preservar los mejores valores. 
- El capitalismo ha dejado de ser la solución de las mayorías en la lucha por alcanzar la justicia social.

- Necesidad del establecimiento de un nuevo tipo de globalización a escala planetaria.

- Contextualización de las ideas en el tránsito hacia una sociedad más justa y humana.

- La nueva sociedad que se construya no puede prescindir de la ética.

- Confianza ilimitada en el hombre para el establecimiento de la globalización de la solidaridad.

- La unidad de todas las fuerzas progresistas es imprescindible para que prevalezcan los mejores valores.

- Necesidad de promover en el hombre una cultura para la paz.

- Necesidad de socializar la información y los logros de la ciencia y la tecnología.

- Desarrollar una cultura del trabajo como primera necesidad vital del hombre, en función de garantizar equidad y justicia social.

\section{Consideraciones finales}

Puede aseverarse que Fidel Castro desarrolla su pensamiento inmerso en la vida y la lucha política, sintetizando en él la obra de pensadores universales que le precedieron como Marx y Lenin, así como autores cubanos, esencialmente Martí, Maceo, Mella, Villena, Guiteras y Camilo. Sus ideas educativas, del trabajo, éticas, de equidad-igualdad y de paz, son referente obligado para todo hombre latinoamericano o del más alejado lugar de este continente que luche por la justicia social. 
La riqueza de la proyección ética de Fidel conduce a la idea del hombre nuevo, a partir no solo de su inteligencia y conocimientos científicos y tecnológicos, sino de su elevada moral, valores, sensibilidad, nobles sentimientos y humanismo, en correspondencia con una realidad social y contexto más humanos. De ahí la influencia de su pensamiento social en el triunfo de la Revolución cubana y en América Latina en la lucha revolucionaria.

Para el profesorado universitario de Historia, las ideas de justicia social presentes en la oratoria de Fidel Castro, constituyen un referente teórico si de formación de estudiantes universitarios se habla, al encontrar en ellos concepciones humanistas en torno a la defensa ética de los derechos desde el cumplimiento de los deberes, sin discriminación sexual, desarrollo físico, origen, edad, color de la piel o cultura se trate.

\section{Referencias}

Abbagnano, N. (2004). Diccionario de Filosofía Parte II. La Habana: Editorial Pueblo y Educación.

Álvarez, P. (2008). Presentación al libro: Habla Fidel. 25 discursos en la Revolución. La Habana: Oficina de Publicaciones del Consejo de Estado.

Betto, F. (1985). Fidel y la Religión. La Habana: Oficina de Publicaciones del Consejo de Estado.

Cárdenas, M. (2007). El pensamiento de Fidel Castro Ruz sobre la educación

[Tesis doctoral inédita]. Villa Clara: Ciencias Pedagógicas.

Castro, F. (1999). Una Revolución solo puede ser hija de la cultura y las ideas. Discurso en el Aula Magna de la Universidad Central de Venezuela el 3 de febrero de 1999. La Habana: Editora Política. 
Castro, F. (200I). Discurso pronunciado el día I5 de marzo. En Transformaciones en las secundarias básicas. Seminario preparatorio del curso escolar 2002-2003. La Habana: Dirección de Secundaria Básica.

Castro, F. (2004, febrero 6). Discurso en la clausura del IV Congreso de Educación Superior. Periódico Granma. La Habana.

Dalton, R. (2009). Sobre dolores de cabeza. Recuperado de: www.palabravirtual.com

Elliot, J. y Dymally, M. (1985). Nada podrá detener la marcha de la Historia. La Habana: Editora Política.

García, G. (1987, agosto 13). El oficio de la palabra hablada. Periódico Juventud Rebelde, pp. 5-7.

Guevara, E. (1970). Cuba ¿Excepción histórica o vanguardia en la lucha anticolonialista? En Obras. 1957-1967. T2. La Habana: Editorial Casa de las Américas.

Diccionario Enciclopédico Color. (1998). Barcelona, España: Grupo Editorial Océano.

Martí, J. (I965). Obras Completas. La Habana: T. I. Editorial Nacional de Cuba.

Martínez, O. (2006, agosto I4). Lo extraordinario de pensar en grande. Periódico Trabajadores, pp. 6-7.

Mencia, M. (1980). La Prisión Fecunda. La Habana: Editora Política.

Milanés, P. (1982). No vivo en una sociedad perfecta. En Yo me quedo (Álbum). La Habana: EGREM-Areito.

184 MINED [Ministerio de Educación de la República de Cuba]. (2008). Seminario Nacional para Educadores No. VIII. La Habana: Editorial Pueblo y Educación.

Ramonet, I. (2006). Cien horas con Fidel. La Habana: Oficina de Publicaciones del Consejo de Estado. 
Real Academia Española. (1970). Diccionario de la Lengua Española. Madrid, España: Editorial Espasa-Calpe.

Rosental, M.; y Iudin, P. (1984). Diccionario filosófico. La Habana: Editorial Revolucionaria.

Ruiz, M. (1995). La enseñanza comunicativa de la lengua y la literatura. México DF: Ediciones INAES.

Este artículo se publica bajo una licencia de Creative Commons Reconocimiento-NoComercial 4.0
Internacional, y puede ser usados gratuitamente para fines no comerciales, dando los créditos a los
autores y a la revista.

Notas

${ }^{\text {I }}$ El término hombre se emplea como sinónimo de género humano. 